\title{
Digital processing of old topographical maps for the reference base for quantitative and qualitative studies of landscape changes
}

\author{
Dariusz Lorek $^{\mathrm{a}, * \text {, Beata Medynska-Gulij }}{ }^{\mathrm{a}}$, Paweł Cybulski ${ }^{\mathrm{a}}$, Tymoteusz Horbinski ${ }^{\mathrm{a}}$, \\ ${ }^{a}$ Affiliation for all authors: Department of Cartography and Geomatics, Adam Mickiewicz University, Poznan, Poland \\ kubal@amu.edu.pl,bmg@amu.edu.pl,p.cybulski@amu.edu.pl,tymoteusz.horbinski@amu.edu.pl \\ * Corresponding author
}

Keywords: Prussian old topographical maps, georeferencing, vectorization, landscape transformations, reference maps

The undertaken issue was the digital processing of cartographic material such as Prussian old topographical maps from the beginning and the end of the XIX century. These maps play a crucial role in studies of the development of the landscape in the past. Quantitative and qualitative changes in geographical space could be analyzed after the transformation of historical material according to the present day coordinate system.

The main source of data were two types of Prussian topographical maps - Urmesstischblätter which represents topographical features from the 1820s and Messtischblätter which depicts the landscape from the 1880s and were based on more precise measurements. These two maps were drawn in the 1:25 000 scale and because of that they are very useful in comparative analysis. Regions presented on them are the Upper Silesia Industrial District and the Ruhr Area.

The main aim of this research was to design and develop a reference basis for further quantitative and qualitative studies of landscape changes in two mentioned regions. The research included a set of methods such as georeferencing old maps based on the current coordinate system, vectorization of the selected geographical features, unification of symbolization, and proofreading of prepared reference maps.

The processing of old cartographic maps was divided into stages which helped to achieve the main goals of the research and gave the results which were reference maps with uniformed style in one coordinate system. These reference maps have also become the basis for the creation of bargraphs of land usage, which are used to describe changes in selected elements of the landscape in individual time periods from 1830 . 